\title{
Quantitative 1D Analysis to Fill Log Acquisition Gaps within the Evaporitic Section for Impedance Modelling Purposes
}

Ciro Climaco (Petrobras), Alexandre Maul (Petrobras), Josué Fonseca (Petrobras), Pablo Barros (Petrobras) \& María González (Emerson)

Copyright 2019, SBGf - Sociedade Brasileira de Geofísica

This paper was prepared for presentation during the $16^{\text {th }}$ International Congress of the Brazilian Geophysical Society held in Rio de Janeiro, Brazil, 19-22 August 2019.

Contents of this paper were reviewed by the Technical Committee of the $16^{\text {th }}$ International Congress of the Brazilian Geophysical Society and do not necessarily represent any position of the SBGf, its officers or members. Electronic reproduction or storage of any part of this paper for commercial purposes without the written consent of the Brazilian Geophysical Society is prohibited.

\section{Abstract}

The evaporitic layer represents the seal for the presalt reservoirs in the Santos Basin, Brazil. It has significant thickness variations and presents different type of rocks, thus it impose substantial velocity contrasts. Therefore, a more realistic description of the internal velocities for the salt section, taking into account the different minerals, can help to reduce problems during seismic processing for instance. Besides, it can serve as input to several other procedures such as the velocity model building for time-depth conversion or depth-depth calibration, the uncertainty analysis regarding depth positioning, and the geomechanical modelling reliability with enhanced processing strategies. In this paper, we will explore a new proposal to estimate profiles within the salt section, where they were not acquired, in order to improve the input for impedance and velocity modelling that honors the presence of salt stratifications.

\section{Introduction}

This study is a step further when compared to the work performed by Amaral et al. (2015), which they provide an application example of the methodology in development since 2014 that is fully described in Maul et al. (2016) to model the salt layers using both seismic and wellbore information.

Currently, the pre-salt reservoirs in the Santos Basin are the most important area for the Brazilian oil industry. The reservoirs are located under water columns, in many cases, bigger than $2,000 \mathrm{~m}$, below $3,000 \mathrm{~m}$ of rocks, including terrigenous sedimentary rocks, albian carbonate rafts and the evaporite section ranging from a few meters to more than $3,000 \mathrm{~m}$ in domes / pillowed areas.

A good seismic acquisition in parallel to the processing techniques application, especially respecting the computational limits have improved, giving better chance to build more plausive seismic images. However, in order to have those enhanced images, reliable velocity models which respect the mathematics and the geology is mandatory. Over the last few years, especially since
2014 , we have observed great improvement regarding the velocity-modelling task.

The proposed methodology aims to better estimate the salt impedance profiles even in depth sections where log data were not acquired. Those impedance profiles will serve as input to build the low frequency model prior to the seismic inversion. Consequently, the seismic inversion information will more correctly situate the different salt stratifications within the evaporitic section. In addition, this result allows us to assign more reliable velocity range for these built stratifications, which provide better chance to perform enhanced depth migration.

Several authors have demonstrated the benefits for the seismic images when considering the insertion of the stratification within the evaporitic section (Maul et al. 2015; Oliveira et al. 2015; Jardim et al. 2015); Meneguim et al. (2015); González et al. 2016). All of them mentioned the first idea presented in Amaral et al. (2015), which was performed in a qualitatively way.

Here, we are presenting a step-further of the method considering a quantitative approach.

\section{Method}

The methodology proposed by Maul et al. (2016) and presented in González et al. (2016) and Gobatto et al. (2016) suggests a recursive approach to the velocity models construction (Figure 1).
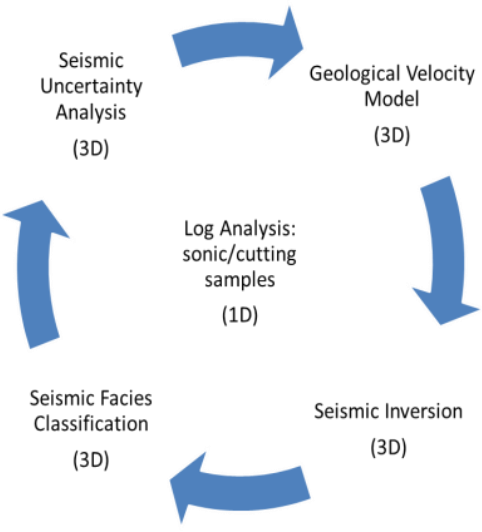

Figure 1: Workflow proposed to generate a more realistic seismic velocity model (adapted from Maul et al., 2016 in González et al., 2016 and Gobatto et al., 2016).

The log analysis is in the center of the workflow, emphasizing its importance to control and calibrate all the 
other steps. However, in the majority of the studied fields within the Santos Basin, we do not have the density log for the entire salt section, even when we have. It is possible to confirm this statement consulting the work presented by Barros et al., 2017 (Figure 2).

\begin{tabular}{|c|c|c|c|c|c|}
\hline & Great Wells & Good wells & $\begin{array}{c}\text { Not-so-good } \\
\text { wells }\end{array}$ & Bad wells & Terrible wells \\
\hline P-sonic & Whole section & $\begin{array}{c}\text { Whole } \\
\text { section }\end{array}$ & Partial & Partial & Partial/None \\
\hline Density & Whole section & Partial & Partial & $\begin{array}{c}\text { None/Very } \\
\text { small section }\end{array}$ & $\begin{array}{c}\text { Very small } \\
\text { section/None }\end{array}$ \\
\hline Rarity & Rare & Common & Common & Very Common & $\begin{array}{c}\text { More common } \\
\text { than we'd like }\end{array}$ \\
\hline
\end{tabular}

Figure 2: Reality of logs in salt section of Santos Basin. Barros et al. (2017).

The salt section commonly presents lacks of log registering for security concerns. The most known reason takes place in the top and the bottom of the salt where the drilling phase-shift takes are located, taking advantage of the stability offered by the superior and basal anhydrites.

Consequently, there is no reason to acquire logs in the cemented area. On the other hand, these gaps affect the confidence on the statistical analysis regarding the mineral occurrences, i.e., the anhydrite is not fully represented and the proportions of other minerals are erroneously represented. For a correct modeling, we need to overcome this problem.

In order to better control the places where we need to fill the gaps of the logs, we follow the statements presented in Amaral et al. (2015) and Yamamoto et al. (2016). Those authors used interpreted lithology strip to control the mineral (LVS, Halite and HVS) occurrence. Therefore, they create pseudo-logs using constant known values.

Meneguim et al. (2015) and Amaral et al. (2015) presented the idea to use constant values to fill the lithology descriptions in a qualitative way. Barros et al. (2017) used it in a quantitative way, prior to perform seismic inversion and got great results. Figure 3 illustrated the log results obtained by the last authors.

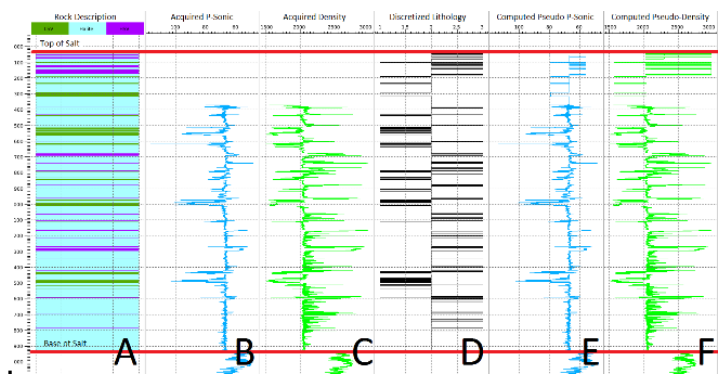

Figure 3: (A) descriptions of the rocks. (B) Sonic log acquired for a given well, with lack of information in part of the evaporitic section. (C) Log density as purchased, also with missing information. (D) Discrete pseudo-facies record, discriminating between "LVS", halite and "HVS", obtained from the interpretation of rocks within the salt section based on "A". (E) All the sonic / pseudo-sonic record, generated by the conclusion of the missing part of the record acquired in " $B$ " with sound values for each class, as seen in " $D$ ". (F) Integer density / pseudo-density register, created by the conclusion of the missing part of the " $C$ " register, applying the correlation of figure 3 to the "sonic" / pseudo-sonic record of "E". Adapted by Barros et la. (2017).

However, in order to perform enhanced model-based seismic inversion to support the velocity model within the salt, sonic and density logs are required and it would be better to have the geological variation of those logs in the missing parts. In this sense, one solution could be a cross-correlation between the different logs, in the part where they do exist, to fill the gaps with a transformation law. In the places where the cross-correlation cannot be calculated, we suggest the use of standard equations, such as Gardner.

\section{Results}

Using the existing sonic and density logs, we generated the relation between the P-Sonic and Density as presented in figure 4. For this specific project, we obtained a 3rd degree polynomial fit from this crosscorrelation.

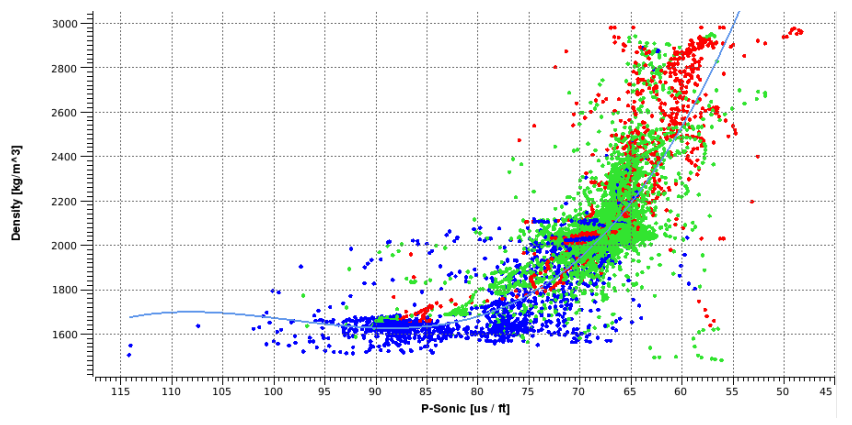

Figure 4: Cross-correlation between P-Sonic and density logs, calculated in the wells where we have complete records. The blue, green and red dots represent low velocity salts, halite and high velocity salts, respectively. The light-blue curve is a 3rd degree polynomial adjusted to all data.

As mentioned before, there are those superior and basal anhydrites as specified in the lithological descriptions that our workflow is able to retrieve. After its application, we recovered the representability of the anhydrite inside the salt section, giving the needed confidence regarding the percentage for the other minerals. Figure 5 illustrated this confidence information. 


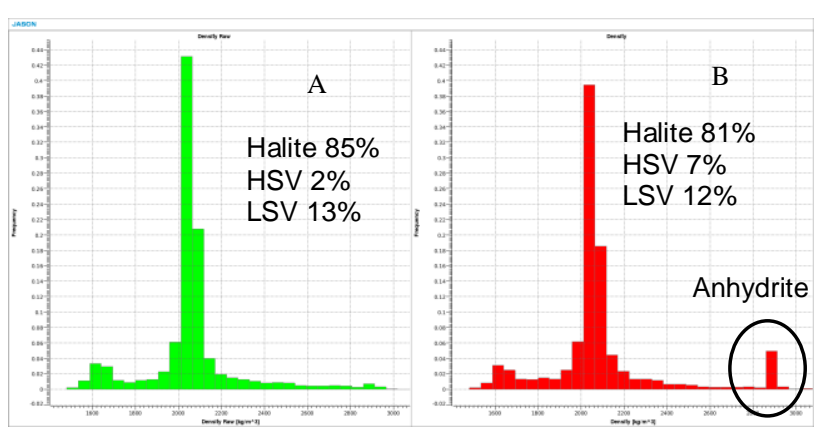

Figure 5: (A) Statistics of log density before the workflow. (B) Statistics of log density after the workflow.

\section{Conclusions}

As discussed previously, the study of pre-salt reservoirs in the Santos Basin is a complex task, due not only to the type of reservoir rocks, but also to the heterogeneity of the overlaying rocks, structural aspects, and the reliability of the seismic images generated with those concerns.

As presented here, there are several ways of dealing with these problems. Many of the consulted works, which deal with the evaporitic section, suggest the usage of seismic inversion to enhance the results. However, the majority of them points as weakness the lack of the log information as they consider it as crucial for the quality of the study.

As the seismic inversion (model-based) requires the well information as complete as possible, we consider the extrapolation of the data correlating the density, the compressional velocity and the lithology strip description to fill any log-gaps as an important step.

The usage of cross-correlation as we stated in this work is a feasible and easy approach to follow. Besides, it preserves the fidelity information and respect all the geological behavior.

As defended by the model-based approach in seismic inversion studies, the well log information must be used to build the low frequency model prior to the inversion task. Therefore, the filling the gaps procedure as described here aim to overcome any missing information during the log acquisition.

In further works, we will consider the uncertainties of the methodology and test the results for all the described applications.

\section{Acknowledgments}

The authors would like to thank Petrobras for giving the support and time for this research, as well as for allowing us to publish the work done.

\section{References}

Amaral, P.J., Maul, A., Falcão, L., González, M. \& González, G., 2015. Estudo Estatístico da Velocidade dos Sais na Camada Evaporítica na Bacia de Santos. (14th International Congress of the Brazilian Geophysical Society 2015) - Rio de Janeiro - RJ, Brazil.
Gobatto, F., Maul, A., Falcão, L., Teixeira, L., Boechat, J.B., González, M. \& González, G., 2016. Refining Velocity Model within the Salt Section in Santos Basin: an Innovative Workflow to include the Existing Stratification and its Considerations. (SEG - Society of Exploration Geophysicist - 2016) - Dallas - TX, USA.

González, M., Gobatto, F., Maul, A., Falcão, L., González, G., Oliveira, L., Meneguim, T. \& Amaral, P.J., 2016. Proposed Workflow to Incorporate Stratification within Salt Section using Velocity and Seismic Attributes - (Third EAGE/SBGf Workshop on Quantitative Seismic Interpretation of Lacustrine Carbonates). Rio de Janeiro - RJ, Brazil.

Jardim, F., Maul, A., Falcão, L., \& González, G., 2015. Estimating Amplitude Uncertainties through Illumination Studies for a Pre-Salt Reservoir. (14th International Congress of the Brazilian Geophysical Society 2015) Rio de Janeiro - RJ, Brazil.

Maul, A., Falcão, L., Gobatto, F., Novellino, V., Jardim, F., Oliveira, L., Meneguim, T., Amaral, P.J., Borges, F., Teixeira, L., Monteiro R.C., González, G. \& González, M., 2016. Incorporação de Estratificações dentro da Seção Evaporítica Utilizando Velocidades e Atributos Sísmicos - (Informe Geofísico da Petrobras - IGP-152 Petrobras Internal Publication).

Maul, A., Jardim, F., Falcão, L., \& González, G., 2015. Observing Amplitude Uncertainties for a Pre-Salt Reservoir Using Illumination Study (Hit-Maps). (77th EAGE Conference \& Exhibition 2015) - Madrid, Spain.

Meneguim, T., Mendes, S.C., Maul, A., Falcão, L., González, M. \& González, G., 2015. Combining Seismic Facies Analysis and Well Information to Guide New Interval Velocity Models for a Pre-Salt Study, Santos Basin, Brazil. (14th International Congress of the Brazilian Geophysical Society 2015) - Rio de Janeiro - RJ, Brazil.

Meneguim, T., Mendes, S.C., Maul, A., Falcão, L. González, M. \& González, G., 2016. Refinamento do Modelo de Reservatórios a partir da Caracterização das Estratificações Salíferas Baseada em Atributos Sísmicos, Pólo Pré-Sal da Bacia de Santos. (48ํㅡㄴ Congresso Brasileiro de Geologia). Porto Alegre - RS, Brazil.

Oliveira, L.C., Falcão, L., Maul, A., Rosseto, J.A., González, M. \& González, G., 2015. Geological Velocity Approach in Order to Obtain a Detailed Velocity Model for the Evaporitic Section, Santos Basin. (14th International Congress of the Brazilian Geophysical Society 2015) Rio de Janeiro - RJ, Brazil

Yamamoto, T., Maul, A., Born, E., Gobatto, F., Campos, M.T. \& González, M., 2016. Incorporação de Estratificações Salíferas Através do Modelo de Velocidade em um Projeto da Bacia de Santos (VII Simpósio Brasileiro de Geofísica - 2016). Ouro Preto MG, Brazil.

Barros, P., Amaral, P., Girard T., Martini, A., Maul, A., \& González, M., 2017. Inversion in the Santos SaltFocused Basin (15th International Congress of the Brazilian Geophysical Society 2017). Rio de Janeiro - RJ, Brazil. 